\title{
Interest exceeds understanding in public support of bee conservation
}

\author{
Joseph S Wilson $^{1 *}$, Matthew L Forister ${ }^{2}$, and Olivia Messinger Carril ${ }^{3}$
}

\begin{abstract}
Recent analyses suggesting that certain populations of bees may be declining have led to a variety of conservation efforts, many of which rely on public support and participation. However, little is known about the public's knowledge of bee diversity. We carried out a survey to measure public understanding of bee diversity and found that although $99 \%$ of respondents believed that bees are critical or important, only $14 \%$ were able to guess within 1000 the actual number of bee species in the US. Furthermore, when reviewing a selection of photographs depicting various insects, many respondents were unable to discern bees from non-bees. Our findings show that even as scientific research on bees has rapidly expanded, the public remains largely uninformed on the subject, especially with regard to the wealth of bee diversity in the US. In light of the fact that conservation efforts require substantial public support, any programs aimed at stopping or mitigating bee population declines will need to include outreach and education measures.
\end{abstract}

Front Ecol Environ 2017; doi:10.1002/fee.1531

$\mathrm{T}_{\mathrm{h}}^{\mathrm{h}}$ he importance of native bees to agricultural and natural landscapes is now broadly accepted by both the scientific community and the public in general. This heightened awareness of bees and their role as pollinators has been motivated in part by recent analyses that suggest some bee communities are experiencing declines (Cameron et al. 2011; Burkle et al. 2013; Goulson et al. 2015). The growing concern about pollinator declines has led to a variety of bee-specific conservation efforts (eg White House Office of the Press Secretary 2014), including those involving citizen scientists (Birkin and Goulson 2015; Martin 2015). While citizen science can successfully contribute to our knowledge of bees (Cohn 2008), it often requires that participants are able to accurately

\section{In a nutshell:}

- Over the past decade, interest in bee conservation, including scientific advances in bee research, has increased markedly; yet many people are largely unaware of the diverse bee fauna in the US

- In a recent survey, we found that the majority of respondents believe bees are important, but greatly underestimated US bee species richness (the median estimate was 50 species, while the true number is approximately 4000 species)

- When asked to confirm whether a given image depicted a bee, many respondents recognized the well-known European honey bee but frequently misidentified common bees as non-bees

- To narrow the gap between the public's interest in bee conservation and the public's understanding of bees, conservation efforts should include improved outreach and education

${ }^{1}$ Department of Biology, Utah State University-Tooele, Tooele, UT*(joeswilson@gmail.com); ${ }^{2}$ Department of Biology, University of Nevada-Reno, Reno, NV; ${ }^{3}$ Santa Fe, NM identify species of interest, or at least distinguish bee species from closely related groups, which may necessitate an elevated level of knowledge (Kremen et al. 2011). Because successful conservation efforts, particularly those concerned with pollinators, require public involvement, it is imperative that conservationists understand the state of knowledge among non-experts who are interested in bees.

In the UK, a number of bumble bee (Bombus) species have undergone severe population declines over the past decade. Several conservation initiatives have specifically addressed this genus, helping to raise awareness about the plight of these species and generating considerable funding for restoration efforts for these and other native bees (Lye et al. 2012; Biodiversity Ireland 2017; Blooms for Bees 2017; Bumblebee Conservation Trust 2017). Nevertheless, a recent survey in the UK found that although over $80 \%$ of respondents reported that they care about bees, fewer than half could name a single bee species and only 3\% knew how many species live in their country (Royal Mail 2015), indicating a gap between awareness and understanding, in spite of conservation and public outreach efforts.

In the US, the health of native bee populations is less well documented than in the UK. Although no species that were historically known east of the Mississippi River appear to have gone extinct in the past 20 years (Colla et al. 2012), large-scale landscape changes over the past 30 years suggest that bee populations native to areas where agricultural land use is particularly high may be severely affected (Koh et al. 2016). One potential way to help imperiled native pollinators in the US is through the conservation efforts of amateur naturalists and other citizen scientists, so that setting aside a modest amount of habitat for native bees becomes commonplace, as it has in the UK for bumble bees. The success of such efforts would rely on a general understanding of the basic needs 
of native bees, whose habitat requirements differ markedly from the more well-known introduced European honey bee (Apis mellifera). How familiar are people in the US with their native bees? Is the ability to visually identify bees associated with personal factors such as education level, self-assessed knowledge of bees, and perceived importance of bees? Here, we present the results of a simple survey that addresses how familiar people are with the bees of the US. For context, we quantify trends in scientific publications and funding with respect to bee research, and discuss how our findings should influence future conservation and outreach efforts associated with native bees.

\section{Materials and methods}

\section{Scientific research related to bees}

To estimate the number of scientific articles on bees published over the past 50 years, we used Google Scholar to search for papers containing both the terms "bee" and "Hymenoptera" anywhere in the article. Results were then pooled across 5-year intervals. For comparison, we also searched for papers during those same 5-year intervals using the term "honey bee". Although "honey bee" and "honeybee" are both frequently used, here we report findings only for "honey bee" because searches of both versions of the common name displayed similar trends. Given that some papers might not include "bee" and "Hymenoptera" in the text and that other papers might include both search terms but not concentrate primarily on bees, our search method likely does not capture all published articles

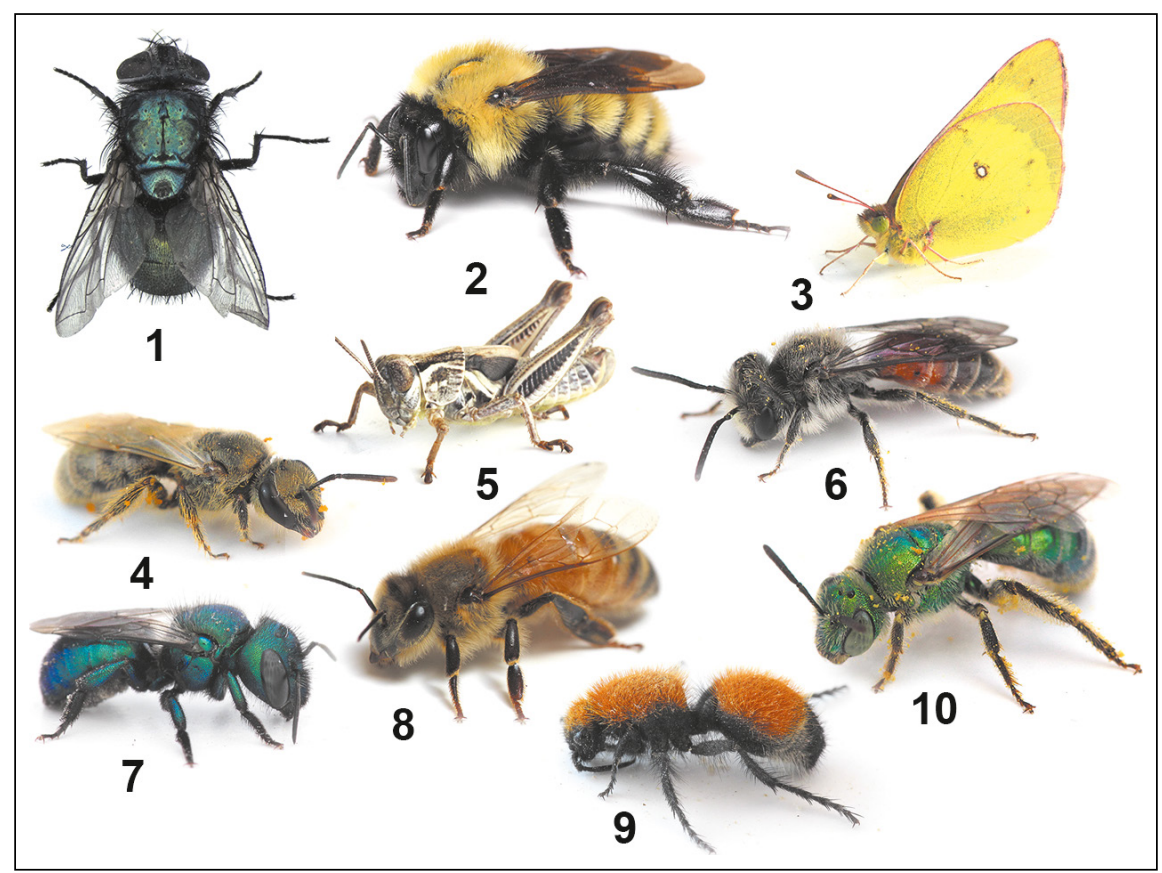

Figure 1. Images of bees and non-bees as they were presented to survey participants. Participants were asked to "mark each number you think is a bee". about bees; however, it does illustrate general trends in published bee research. Furthermore, to estimate the monetary investment in scientific research devoted to bees, we investigated the online datasets of the US National Science Foundation (NSF) to determine the amount of funding awarded to bee-related projects over the past 30 years.

\section{Survey}

Our survey addressed not only knowledge of bee diversity in the US but also the degree of perceived importance of bees. First, we asked if participants considered bees to be (1) "unimportant", (2) "somewhat unimportant", (3) "neither important nor unimportant", (4) "somewhat important", or (5) "critical". Next, we asked participants to estimate the number of bee species living in the US. We then showed them a collage of ten insect images (depicting six bees and four non-bees) and asked them to identify each image as either a bee or a non-bee (Figure 1). Finally, we asked participants to report two additional personal factors: the highest education level they had completed ([1] high-school degree, [2] bachelor's degree, [3] master's degree, [4] $\mathrm{PhD}$, or [5] none of the above) and how knowledgeable they considered themselves about bees ([1] "not at all knowledgeable", [2] "not very knowledgeable", [3] "somewhat knowledgeable", and [4] "very knowledgeable").

We recruited survey participants by word of mouth and through social media (including Twitter, Instagram, and Facebook) and by posting the survey link on a variety of "community pages" (eg Tooele County 411; https://www. facebook.com/groups/TooeleCounty411). The link was also distributed by email to professors at several universities to share with their classes. Survey participants were encouraged to share the link on their personal social media pages. Participation was strictly voluntary and all participant data were collected and anonymized using the online survey tools available at Qualtrics.com. Survey methodology and recruitment procedures were approved through Utah State University's Institutional Review Board. We note that sharing the survey via social media might have produced a sample biased toward individuals that share similar interests - in this case, an interest in bees. Thus, our results should be considered a potential overestimate of public understanding about bees, although the extent of this overestimation cannot be quantified at this time. 


\section{Statistical methods}

To understand the relationship between the survey participants' personal factors and their estimates of the number of US bee species, we used a simple multiple regression with the following independent variables (all of which were treated as ordinal factors): education level, self-assessed knowledge of bees, and perceived importance of bees. The response variable was the over- or underestimation of the correct number of bee species, on a log scale. In other words, we calculated: $\log ($ estimated number of species $)-\log (4000)$. A small number of extreme values (estimates greater than 1 million) were excluded from analyses because such values raised the possibility that individuals misunderstood the question or made a mistake when entering their answers.

To investigate the influence of personal factors on the ability to identify images of insects as bees or non-bees, we performed a logistic regression on the identification (either correct or incorrect) of each image as predicted by the three ordinal independent variables described above. We also included the number of seconds to complete the entire survey ("duration") as a continuous covariate for effort.

Finally, we used an exact binomial test to determine whether the number of images correctly identified as bees or non-bees was significantly different from what would be expected with a $50 \%$ probability of guessing the right answer. We investigated all model assumptions, performed statistical analyses using $\mathrm{R}$ (version 2.15.0; $\mathrm{R}$ Core Team 2014), and archived related datasets on Dryad.

\section{Results}

\section{Scientific advances related to bees}

In the past 50 years, the number of scientific papers published about bees (search terms "bee" and "Hymenoptera") increased by a factor of 20 (711 papers between 1965 and 1969 versus 15,900 articles between 2010 and 2014). These articles likely included studies on solitary bees as well as honey bees. Indeed, during the same time period, the number of scholarly publications including only the latter taxon (search term "honey bee") increased by a factor of 18 (1190 papers between 1965 and 1969 versus 22,500 papers between 2010 and 2014). Similarly, over the past 30 years, NSF funding for bee-related projects in the US increased by a factor of 20 , while the total NSF budget increased only by a factor of 5 .

\section{Estimates of bee richness}

Of 1499 completed surveys, we included only 1427 in our analysis; we excluded participants who spent more than 5 minutes to finish the survey. Ninety-nine percent

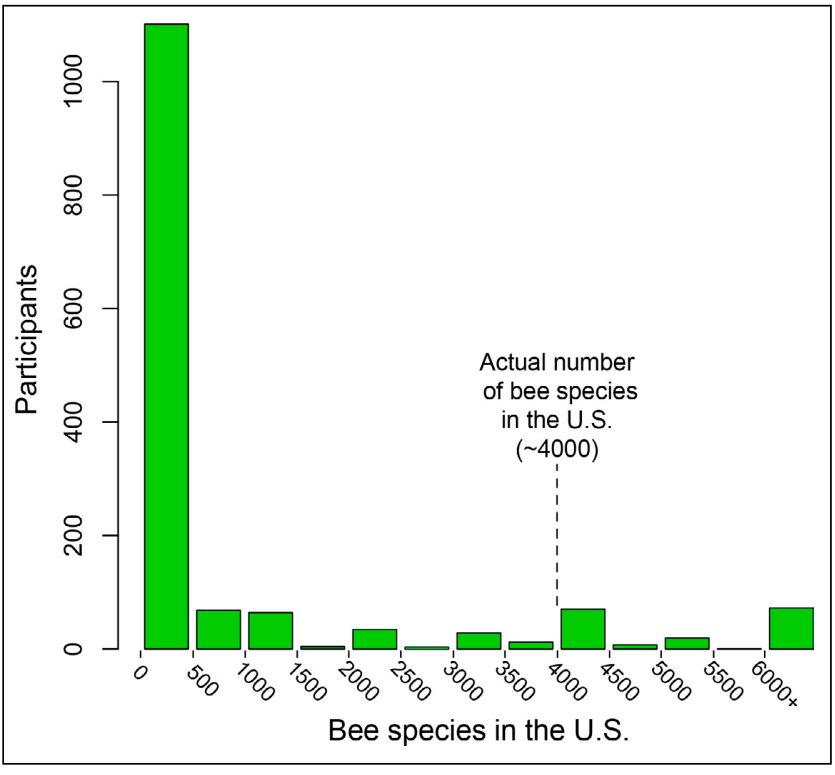

Figure 2. Histogram showing the number of bee species estimated to occur in the US by survey respondents. The actual number of bee species is indicated by the dashed vertical line.

of respondents reported that bees were either "critical" or "somewhat important", but only $14 \%$ were able to guess within 1000 the number of species in the US (approximately 4000 species). Over 79\% of participants underestimated species richness by an order of magnitude or more (Figure 2). The median number of bee species presumed to occur in the US by survey participants was 50; this value did not include 24 individuals who answered that there were between one million and one trillion species. Participants' over- or underestimation of the total number of bee species in the US was successfully modeled with a simple multiple regression that revealed a strong effect of self-described knowledge about bees $\left(F_{3,983}=24.74, P<0.001\right)$ and a weaker effect of education level $\left(F_{4,983}=2.38, P=0.0498\right)$, while perceived importance of bees did not have a detectable effect $\left(F_{1,983}=2.023, P=0.15\right)$. The last result can likely be explained by the lack of variation in response to that issue (less than 1\% of respondents said that bees were anything less than "somewhat important").

\section{Ability to identify bees}

In contrast to the general miscalculation of the number of bee species in the US, we found that participants on average correctly identified the six images of bees as bees $70 \%$ of the time; if the bumble bee and honey bee images were excluded, participants on average correctly identified the remaining four bee images as bees $57.4 \%$ of the time, which was significantly better than a 50/50 chance of success (exact binomial test, $P<0.001)$. The percentages of successful identification for each bee were as follows (Figure 3): a bumble bee (95.5\%), a honey bee (95.2\%), a sweat bee (Lasioglossum) 


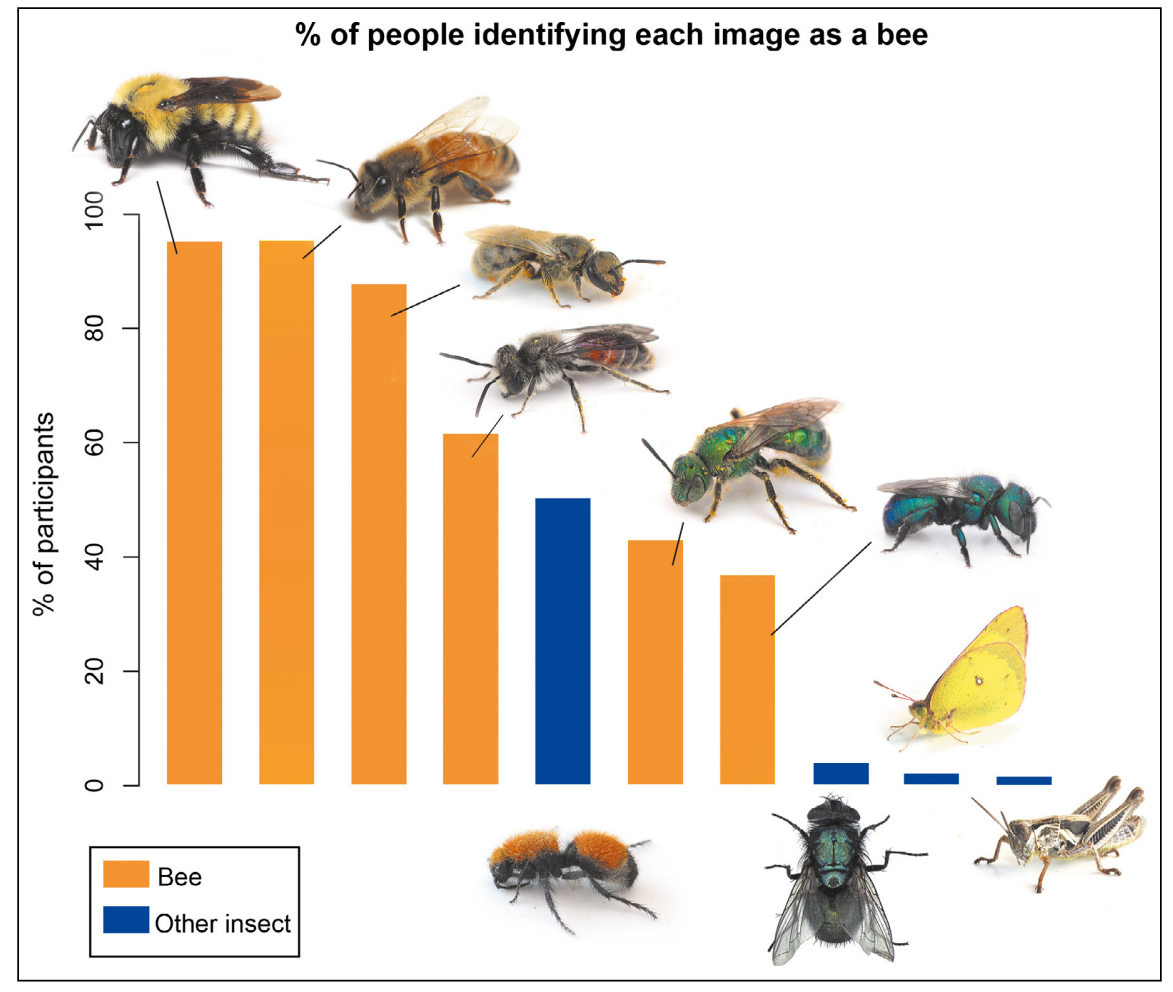

Figure 3. Bar graph showing the percentage of participants that thought each of the ten images was a bee. Orange bars represent bees, whereas blue bars represent insects other than bees.

(88.0\%), a mining bee (Andrena) (61.9\%), a metallic green sweat bee (Agapostemon) (42.7\%), and a mason bee (Osmia) (36.8\%). The bumble bee and honey bee, therefore, were correctly identified as bees by most participants, but other very common North American bee species were not as easily recognized. The majority of respondents successfully noted that a fly, a butterfly, and a grasshopper were not bees, but were less successful at recognizing that a velvet ant was not a bee (Figure 3). Similar to the model predicting participants' estimation of the number of US bee species, the ability to recognize which images depicted bees - and which images did not - was affected by level of education $\left(\chi^{2}=26.47, P<0.001\right)$ and by self-described knowledge of bees $\left(\chi^{2}=58.52, P<0.001\right)$, while the perceived importance of bees did not have an effect $\left(\chi^{2}=0.32, P=0.57\right.$ ) (Figure 4$)$. The number of seconds spent on the survey was a significant covariate $\left(\chi^{2}=6.34, P=0.012\right)$.

\section{Discussion}

Nearly 4000 bee species are found in the US. Though few of these species are managed for their pollination services, they are nonetheless essential to sustaining the fruit and seed set of the majority of the regions' flowering plants (Axelrod 1960; Klein et al. 2007; Ollerton et al. 2011). The absence of these species has been associated with, among other things, substantial shifts in the structure of plant-pollinator networks (Kaiser-Bunbury et al. 2010; Lever et al. 2014), genetic isolation between plant populations (Aguilar et al. 2006; Tepedino et al. 2014), limits to geographic ranges of plants (eg Moeller et al. 2012), the loss of endangered plant species (eg Chi and Molano-Flores 2015), and changes in reproductive strategies for some flowering plants (eg Ruan et al. 2009). In agricultural habitats, even in the presence of managed honey bee colonies, native bees are major contributors to the pollination of crops (eg Mandelik et al. 2012; Rader et al. 2013), and their absence can make a significant difference in fruit set (Garibaldi et al. 2013). While the health and stability of native bee populations and communities remains poorly understood (Bartomeus and Winfree 2013; Ghazoul 2015), several lines of evidence suggest that some species may be imperiled, given that agricultural intensification (Koh et al. 2016) and non-bee-friendly agricultural practices (eg Shuler et al. 2005), including pesticide use, might all be negatively affecting bee populations (Hladik et al. 2016).

A growing community of naturalists, environmentalists, and other concerned citizens has expressed an interest in "saving the bees". We assume this desire will be more productively implemented when combined with an improved understanding of the bees one aims to save. Although our findings suggest that survey participants are aware of the importance of bees, there appears to be a gap between intention and understanding. In particular, while most participants correctly identified images of honey bees and bumble bees as bee species, fewer participants correctly identified images of the other bees in the survey; such an outcome could lead to poor or misguided efforts to help protect jeopardized pollinator populations. For example, a backyard garden has the potential to be an important resource for native bees as well as honey bees. However, if only the latter is recognized by the land owner, then a garden's native bees might not be provided for in terms of nesting sites and appropriate floral hosts.

Our findings demonstrate that even as scientific research on native bees - including their natural history, ecological importance, and population status - has grown, members of the public have not been made aware of, and are therefore unable to recognize, the diversity of bees around them. Because media attention has concentrated almost exclusively on the honey bee over the last 15 years, it is perhaps not surprising that most people 
have not been given the opportunity to learn about other kinds of bees. While a focus on the honey bee has drawn attention to the importance of pollination services, it has not advanced advocacy for native wild bees. As an example, recent research suggests that management practices designed to be "pollinator friendly" have done little to support wild bees in Europe (Wood et al. 2015), possibly due to the lack of understanding of both the presence and needs of bees other than bumble bee species and the honey bee.

Practicing land stewardship that accommodates wild bees, at any scale, is not possible if stewards have not been informed about the existence of wild bees. Raising awareness about the diverse bees of the US, and their specific needs, could be mutually beneficial for bees and for those with an interest in bees, both amateurs and professionals. When outreach efforts improve understanding of biodiversity, they also increase appreciation and willingness to preserve that biodiversity (Kaplan 2000; Frantz and Mayer 2014). Moreover, enhanced human well-being has been linked to awareness of species richness in the environment (McKinney 2002) and exposure to natural processes (Ulrich et al. 1991). The marked success of a number of citizen-science programs, especially for birds (Silvertown 2009; Dickinson et al. 2010), suggests that similar programs might be successful with native bees. Several organizations have recently attempted to fill this void for bees (Ascher and Pickering 2016; Bug Guide 2017; The Xerces Society 2017; USGS Bee Inventory and Monitoring Lab 2017).

Scientists may feel, as has been observed in other conservation scenarios (Nabhan 1995), that because the majority of people already believe the issue (in this case, the need to protect bees) to be important, knowing the specifics is less important. As conserving pollinators is the end goal, does it matter that many people have trouble recognizing species other than the bumble bee and honey bee? Without effective outreach and education about native bees, the efforts of those concerned about bee declines may in some cases do more harm than good. For example, well-meaning individuals, in an effort to "save the bees", are installing honey bee hives in residential backyards; the unfortunate outcome is competition between the honey bees and native bees in areas where floral resources are scarce (Roubik and Wolda 2001; (c)

(d)
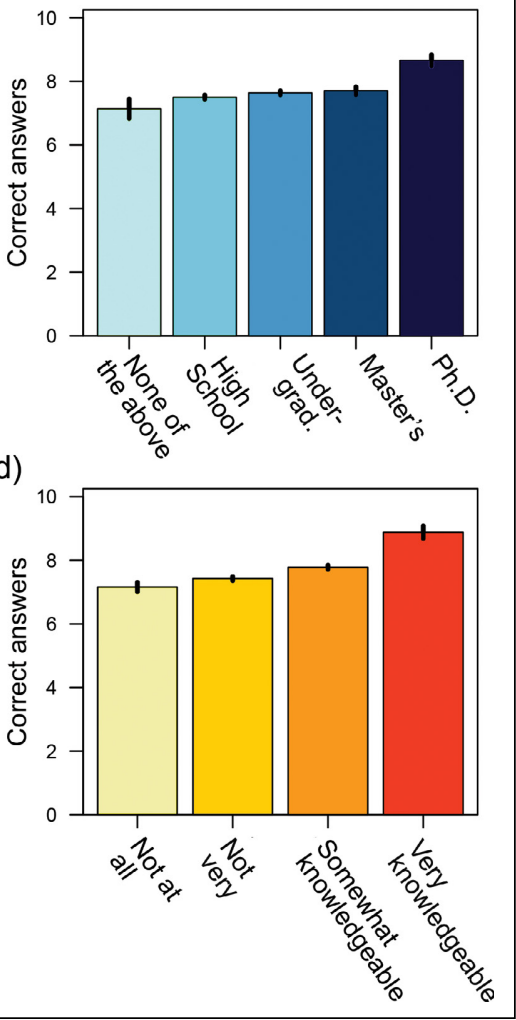

Figure 4. Summary of survey results. In (a) and (b), the estimated numbers of bee species are shown as notched box plots (the "notch" shows the median) for the participants giving different answers by level of education (a) and self-described nowledge of bees $(b)$. The dashed horizontal line is the correct number of species $(4000)$; note the $y$ axis is on a log scale. In (c) and (d), the numbers of correct answers (across the ten images to be identified) are shown for the different categories of participants (error bars are standard errors).

Thomson 2004; Cane and Tepedino 2016). Moreover, honey bee colonies imported from non-local sources can spread diseases (Klee et al. 2007), and are therefore less likely to help either declining honey bees or native bees (Graystock et al. 2016). Even native bee houses that are constructed from inappropriate materials, or are improperly maintained, may not actually help bees that use them (MacIvor and Packer 2015). "Bee-friendly gardens" planted with invasive plants and cultivars may be wellintentioned but ultimately unhelpful to resident bee populations in certain areas or ecological contexts (Razanajatovo et al. 2015). In particular, plants that are "honey bee friendly" are often different from those that are "native bee friendly" (Memmott and Waser 2002; Frankie et al. 2013).

Native bees are an ideal model for raising awareness about a number of conservation agendas and ecological topics, including plant-animal interactions, invertebrate biodiversity, and the effects of human alterations on the landscape. Bees are diverse, aesthetically pleasing, and approachable, often residing in heavily modified environments and lending themselves well to 
observation by curious individuals in urban or suburban areas (Wilson and Carril 2016). The lack of bee-related knowledge by many people in the US reveals a unique opportunity: it is perhaps unusual to find a community of individuals already rallied behind a campaign ("save the bees!") but who have not had the chance to learn even the most basic relevant scientific information (such as the number of bee species in the US). We encourage biologists and educators alike to take advantage of this situation to develop and implement native bee-centered outreach materials, aimed at educating people about both the importance and diversity of native bees.

\section{Acknowledgements}

We thank $\mathrm{T}$ Griswold and $\mathrm{H}$ Ikerd for advice on project design, as well as the survey participants and those who helped spread it through social media. Ethics: Utah State University's IRB approved the methods followed in this study (Protocol \#4671).

\section{References}

Aguilar R, Ashworth L, Galetto L, et al. 2006. Plant reproductive susceptibility to habitat fragmentation: review and synthesis through a meta-analysis. Ecol Lett 9: 968-80.

Ascher JS and Pickering J. 2016. Discover Life bee species guide and world checklist (Hymenoptera: Apoidea: Anthophila). www.discoverlife.org $/ \mathrm{mp} / 20 \mathrm{q}$ ?guide=Apoidea_species. Viewed 23 Jan 2017.

Axelrod DI. 1960. The evolution of flowering plants. Chicago, IL: University of Chicago Press.

Bartomeus I and Winfree R. 2013. Pollinator declines: reconciling scales and implications for ecosystem services. F1000 Res 2: 146.

Biodiversity Ireland. 2017. www.biodiversityireland.ie/record-biodiversity/surveys/bumblebee-monitoring-scheme. Viewed 23 Jan 2017.

Birkin L and Goulson D. 2015. Using citizen science to monitor pollination services. Ecol Entomol 40: 3-11.

Blooms for Bees. 2017. www.bloomsforbees.co.uk. Viewed 23 Jan 2017.

Bug Guide. 2017. http://bugguide.net/node/view/15740. Viewed 23 Jan 2017.

Bumblebee Conservation Trust. 2017. http://bumblebeeconservation.org. Viewed 23 Jan 2017.

Burkle LA, Marlin JC, and Knight TM. 2013. Plant-pollinator interactions over 120 years: loss of species, co-occurrence, and function. Science 339: 1611-15.

Cameron SA, Lozier JD, Strange JP, et al. 2011. Patterns of widespread decline in North American bumble bees. P Natl Acad Sci USA 108: 662-67.

Cane JH and Tepedino VJ. 2016. Gauging the effect of honey bee pollen collection on native bee communities. Conserv Lett 10: 205-10.

Chi K and Molano-Flores B. 2015. Degradation of habitat disrupts plant-pollinator interactions for a rare self-compatible plant. Plant Ecol 216: 1275-83.

Cohn JP. 2008. Citizen science: can volunteers do real research? BioScience 58: 192-97.

Colla SR, Ascher JS, Arduser M, et al. 2012. Documenting persistence of most eastern North American bee species (Hymenoptera: Apoidea: Anthophila) to 1990-2009. J Kan sas Entomol Soc 85: 14-22.
Dickinson JL, Zuckerberg B, and Bonter DN. 2010. Citizen science as an ecological research tool: challenges and benefits. Annu Rev Ecol Evol Syst 41: 149-72.

Frankie GW, Vinson SB, Rizzardi MA, et al. 2013. Relationships of bees to host ornamental and weedy flowers in urban Northwest Guanacaste Province, Costa Rica. J Kansas Entomol Soc 86: 325-51.

Frantz CM and Mayer FS. 2014. The importance of connection to nature in assessing environmental education programs. Studies Educ Eval 41: 85-89.

Garibaldi LA, Steffan-Dewenter I, Winfree R, et al. 2013. Wild pollinators enhance fruit set of crops regardless of honey bee abundance. Science 339: 1608-11.

Ghazoul J. 2015. Qualifying pollinator decline evidence. Science 348: $981-82$.

Goulson D, Nicholls E, Botías C, et al. 2015. Bee declines driven by combined stress from parasites, pesticides, and lack of flowers. Science 347: 1255957.

Graystock P, Blane EJ, McFrederick QS, et al. 2016. Do managed bees drive parasite spread and emergence in wild bees? Int $J$ Parasitol Parasites Wildl 5: 64-75.

Hladik ML, Vandever M, and Smalling KL. 2016. Exposure of native bees foraging in an agricultural landscape to current-use pesticides. Sci Total Environ 542: 469-77.

Kaiser-Bunbury CN, Muff S, Memmott J, et al. 2010. The robustness of pollination networks to the loss of species and interactions: a quantitative approach incorporating pollinator behaviour. Ecol Lett 13: 442-52.

Kaplan S. 2000. New ways to promote proenvironmental behavior: human nature and environmentally responsible behavior. J Soc Issues 56: 491-508.

Klee J, Besana AM, Genersch E, et al. 2007. Widespread dispersal of the microsporidian Nosema ceranae, an emergent pathogen of the western honey bee, Apis mellifera. J Invertebr Pathol 96: $1-10$.

Klein AM, Vaissiere BE, Cane JH, et al. 2007. Importance of pollinators in changing landscapes for world crops. Proc $R$ Soc $B$ 274: 303-13.

Koh I, Lonsdorf EV, Williams NM, et al. 2016. Modeling the status, trends, and impacts of wild bee abundance in the United States. P Natl Acad Sci USA 113: 140-45.

Kremen C, Ullman KS, and Thorp RW. 2011. Evaluating the quality of citizen-scientist data on pollinator communities. Conserv Biol 25: 607-17.

Lever JJ, Nes EH, Scheffer M, et al. 2014. The sudden collapse of pollinator communities. Ecol Lett 17: 350-59.

Lye GC, Osborne JL, Park KJ, et al. 2012. Using citizen science to monitor Bombus populations in the UK: nesting ecology and relative abundance in the urban environment. J Insect Conserv 16: 697-707.

MacIvor JS and Packer L. 2015. "Bee hotels" as tools for native pollinator conservation: a premature verdict? PLOS ONE 10: e0122126.

Mandelik Y, Winfree R, Neeson T, et al. 2012. Complementary habitat use by wild bees in agro-natural landscapes. Ecol Appl 22: $1535-46$.

Martin C. 2015. A re-examination of the pollinator crisis. Curr Biol 25: R811-15.

McKinney ML. 2002. Urbanization, biodiversity, and conservation. BioScience 52: 883-90.

Memmott J and Waser NM. 2002. Integration of alien plants into a native flower-pollinator visitation web. Proc $R \operatorname{Soc} B$ 269: 2395-99.

Moeller DA, Geber MA, Eckhart VM, et al. 2012. Reduced pollinator service and elevated pollen limitation at the geographic range limit of an annual plant. Ecology 93: 1036-48.

Nabhan GP. 1995. The dangers of reductionism in biodiversity conservation. Conserv Biol 9: 479-81. 
Ollerton J, Winfree R, and Tarrant S. 2011. How many flowering plants are pollinated by animals? Oikos 120: 321-26.

R Core Team. 2014. R: a language and environment for statistical computing. www.r-project.org. Vienna, Austria: R Foundation for Statistical Computing.

Rader R, Reilly J, Bartomeus I, et al. 2013. Native bees buffer the negative impact of climate warming on honey bee pollination of watermelon crops. Global Change Biol 19: 3103-10.

Razanajatovo M, Föhr C, Fischer M, et al. 2015. Non-naturalized alien plants receive fewer flower visits than naturalized and native plants in a Swiss botanical garden. Biol Conserv 182: 109-16.

Roubik DW and Wolda H. 2001. Do competing honey bees matter? Dynamics and abundance of native bees before and after honey bee invasion. Popul Ecol 43: 53-62.

Royal Mail. 2015. Royal Mail issues special stamps illustrating the beauty of British bees. www.royalmailgroup.com/royal-mail-issues-special-stamps-illustrating-beauty-british-bees. Viewed 23 Jan 2017.

Ruan CJ, Mopper S, da Silva JT, et al. 2009. Context-dependent style curvature in Kosteletzkya virginica (Malvaceae) offers reproductive assurance under unpredictable pollinator environments. Plant Syst Evol 277: 207-15.

Shuler RE, Roulston TH, and Farris GE. 2005. Farming practices influence wild pollinator populations on squash and pumpkin. J Econ Entomol 98: 790-95.
Silvertown J. 2009. A new dawn for citizen science. Trends Ecol Evol 24: 467-71.

Tepedino VJ, Mull J, Griswold TL, et al. 2014. Reproduction and pollination of the endangered dwarf bear-poppy Arctomecon humilis (Papaveraceae) across a quarter century: unraveling of a pollination web? West N Am Nat 74: 311-24.

The Xerces Society. 2017. www.xerces.org. Viewed 23 Jan 2017.

Thomson D. 2004. Competitive interactions between the invasive European honey bee and native bumble bees. Ecology 85: 458-70.

Ulrich RS, Simons RF, Losito BD, et al. 1991. Stress recovery during exposure to natural and urban environments. J Environ Psychol 11: 201-30.

USGS Bee Inventory and Monitoring Lab. 2017. www.flickr.com/ photos/usgsbiml. Viewed Jan 232017.

White House Office of the Press Secretary. 2014. Presidential Memorandum - Creating a Federal Strategy to Promote the Health of Honey Bees and Other Pollinators. http://bit.ly/ 2jFVV1C. Viewed 21 Jan 2017.

Wilson JS and Carril OJM. 2016. The bees in your backyard: a guide to North America's bees. Princeton, NJ: Princeton University Press.

Wood TJ, Holland JM, and Goulson D. 2015. Pollinator-friendly management does not increase the diversity of farmland bees and wasps. Biol Conserv 187: 120-26. 